\title{
Issues of Legitimacy for Children of Polygamous Marriage in US Immigration Practices
}

\author{
Kenneth I. Granle Jr. \\ Mitchell Hamline School of Law, Saint Paul, UNITED STATES
}

Received: 31 March 2020 • Accepted: 2 June 2020 • Published Online: 18 July 2020

\begin{abstract}
The government of the United States does not recognize the children of polygamous marriages abroad as legitimate, causing myriad issues for a significant number of immigrants seeking citizenship through derivation. The proposal put forth in this article suggests that the US government automatically recognize these children as legitimate and stop requiring them to provide further proof of their legitimacy. A review of case law in which questions of legitimacy have been answered by relying on a petitioner's country of origin will show that the US government already accepts other foreign practices concerning marriage and children. Additionally, further issues surrounding polygamy, legitimation, and US immigration practices will be addressed.
\end{abstract}

Keywords: immigration, polygamy, derivation of citizenship, legitimacy, US law.

\section{Introduction}

Immigration practices in the United States are ever evolving, much like in the rest of the world. While significant advances and reforms have passed that allow more individuals to benefit from various forms of immigration relief, there are still many reasons for comprehensive immigration reform. One such area is the US government's refusal to recognize the legitimacy of children born to polygamous marriages abroad. This means that a child born legitimately in one country might not be deemed as legitimate through immigration proceedings in the United States. It is true that there are ways for non-traditional families to find immigration relief, but they are mostly acquired by admitting that the family is not actually a family, that some marriages are not real, and that certain children are in fact illegitimate.

Recognizing polygamous marriages is not something that US immigration law is ready to do, but the children of such marriages should not suffer just because they are not the children of the first wife. Therefore, the current practice of not recognizing children of second, third, or even fourth wives needs comprehensive reform. Such children should receive the full rights and privileges as other children for immigration purposes. Doing so would make derivation of citizenship easier for millions of children, remove a significant amount of paperwork from the already inundated immigration system, and restore a sense of dignity to individuals seeking to derive citizenship from someone that they have always seen as their father.

While there are more politically correct ways to refer to the children in question, the proposal presented in this paper will use the term "illegitimate" for the sake of consistency as it is

(C) Authors. Terms and conditions of Creative Commons Attribution 4.0 International (CC BY 4.0) apply. Correspondence: Kenneth I. Granle Jr., Mitchell Hamline School of Law, Saint Paul, UNITED STATES. E-mail: kenneth.granle@mitchellhamline.edu. 
the term used in US immigration law. In addition, the law is silent on whether a polygamous marriage affects the eligibility of the children of the first spouse, but the standard practice shows that it does not.

\subsection{The definition of child}

Before delving further into this quagmire, it is important to solidify the term "child" as it is used in US immigration practices. According to US law, we can define this term a few different ways, depending on the specific intention of the petition or act. The US Immigration and Naturalization Act (INA) defines it in two different ways, depending on the circumstances of the birth of the supposed "child". INA $\S 101(b)(1)$ defines a child as "an unmarried person under twenty-one years of age who is..." either born in wedlock, a stepchild, adopted, or has been legitimated. This definition is what the government of the United States uses when it issues immigrant and nonimmigrant visas. However, for naturalization purposes and derivation of citizenship, there is a different definition. INA §101(c)(1) states:

"The term "child" means an unmarried person under twenty-one years of age and includes a child legitimated under the law of the child's residence or domicile, or under the law of the father's residence or domicile, whether in the United States or elsewhere..."

The definition continues by explaining how adopted children factor into this framework as well as legal custody. Though these definitions are very similar, their unique nuances can have a huge impact in determining whether a potential immigrant can receive the relief or benefits sought. The most important thing to know, when considering the second definition and the point of this proposal, is that the act clearly states that immigration courts must consider the laws of the child's country of origin when handling issues of legitimacy.

\subsection{Derivation of citizenship}

Legitimacy issues primarily arise in US immigration proceeding when an applicant seeks to derive citizenship from their father. INA $\S 320$ allows the child of a US citizen who was born outside the United States to derive citizenship from a parent who is a citizen. The parent in question may have been born a citizen or acquired their citizenship through naturalization. There are certain stipulations, including the age and location of this child in question, but one important caveat is that a child born outside of wedlock must prove that they received legitimation prior to their eighteenth birthday. Immigrant families can accomplish this in several ways, but many lack the funding and resources to do so. Thus, it becomes problematic when claims of illegitimacy arise.

\section{Methodology}

The following will review seminal cases concerning individuals seeking various forms of immigration relief. Each of these cases contains a petitioner whose legitimacy was brought into question during their immigration proceedings, and the determination of which ultimately affected the outcome of the case. Particular emphasis will be placed on the US court system's recognition of external legitimacy practices and its willingness to accept children as legitimate when they do not immediately conform to US societal norms. There will also be some commentary on the state of polygamy in the world as well as recommendations for future legislation concerning children of polygamous marriages in immigration proceedings. 


\section{Discussion}

There is practically no case law concerning children of second or third wives and naturalization. This is because legitimation can be proven through many different means and most petitioners will begrudgingly submit the proper documentation to prove that they obtained legitimation prior to their eighteenth birthday. When legitimation does arise in the courts, it is usually in a situation where parents were not married and fathers were not always present. However, an analysis of such cases does reveal a particularly interesting notion: the laws and customs of an immigrant's country of origin more often than not answer questions of legitimation. This is a rare occurrence in US jurisprudence, including immigration law.

It should be noted that these issues of legitimation almost only arise when a petitioner seeks to derive citizenship through a US-citizen father; for obvious reasons, legitimation issues do not commonly arise when the US-citizen parent is the petitioner's mother.

\subsection{Elimination of distinction}

One of the first cases to defer to another country's laws pertaining to legitimation was Matter of Clahar (1981) which concerned two individuals who sought immigration relief through their link as brother and sister. According to INA §101(b)(1), to derive immigration benefits as siblings, the two people must both be "children" of a common "parent", those words being read with their immigration definitions and not plain meaning. The individuals in Clahar had been born to different mothers, neither of whom the record indicates was married to their shared father. Jamaica has an interesting history concerning its stance on legitimation of children. In 1909, the government of Jamaica enacted what would become known as the Jamaican Status of Children Act, which confirmed legitimate status on many children who had been born out of wedlock. Even with the invocation of this act, the brother and sister in Clahar could not claim that they had been legitimated since none of their parents had even been married, even after their respective births. However, the Jamaican Status of Children Act basically eliminated the distinction between legitimate and illegitimate children (Matter of Clahar: 4). Individuals, whether they had been born legitimate, legitimated, or always illegitimate, could all be deemed "children" of their fathers in the same capacity. Therefore, while the government of Jamaica has enacted provisions that allow many more children to claim legitimacy, it has also removed any real potency from the distinction. As the Legitimation Act of Jamaica has yet to be repealed, this shows that being labeled as legitimate or illegitimate is still important to people even if it has no actual impact on their status or rights. Even as the world moves away from being concerned with legitimacy, people still find it personally important and it can have a significant effect on their identity.

There is a significant correlation between the acceptance that comes with being considered legitimate by society and one's self-esteem. Children, who have been deemed illegitimate, whether by society or a government agency, tend to exhibit low self-esteem (Maldonado, 2011) and can actually have stunted cognitive development (Silverstein \& Auerbach, 1999). While this may not be surprising for children who have been told they are illegitimate they entire lives, the traumatic effect this can have on adults who have considered themselves legitimate until the US government says otherwise is practically unconscionable. Even after they have proved by some means that they obtained legitimation prior to their eighteenth birthday, requiring a petitioner to admit that they were at one time an illegitimate child still has the potential to damage their reputation and self-worth.

The brother and sister in Clahar were not able to claim legitimacy as their shared father had never married either of their mothers, but the Jamaican Status of Children Act could have allowed them to have a viable claim to siblinghood. However, this particular act was ill timed for the brother and sister in Clahar. To obtain the immigration relief that they sought, the court 
found that "it must be demonstrated that both parties once qualified as the "child" of a common "parent"..." (Matter of Clahar: 5). When the Jamaican Status of Child Act came into effect, both the brother and sister in Clahar were above the age of eighteen (p. 6) and had no retroactive or nunc pro tunc effects. Therefore, even though the act allowed the siblings the ability to claim the same rights and privileges as legitimate or legitimated children in Jamaica, they had never been able to do so as minors and therefore could not claim to be the "children" of the same "parent" for US immigration purposes.

Numerous countries have sought to eliminate the distinction between legitimate and illegitimate children for various reasons. In some regards, it is because the international community has recognized that children should not be made to suffer or feel inferior because of the actions of their parents. Another reason may be that governments have realized that the elimination of such distinction and bias makes it easier for their citizens to emigrate to more affluent countries. The Guyanese Removal of Discrimination Act was one such attempt to put all children on a level playing field. It features prominently in Matter of Goorahoo (1994), another case of US immigration courts relying on laws of an immigrant's country of origin to determine whether they can be claimed as a child for immigration purposes. In Goorahoo, a lawful permanent resident sought to bring his young son from Guyana to the United States; the child's parents had never been married, but both parents' names were on the child's birth certificate and the father had contributed greatly to the child's upbringing. In lieu of determining whether the child had been formally legitimated by his father before he left Guyana, the court considered the Removal of Discrimination Act and its effect on the child. The act had been in effect since before the child's birth, so this situation differs from Clahar in that regard. The court ultimately found that "...when the country where the child was born eliminates all legal distinctions between legitimate and illegitimate children, all children are deemed to be the legitimate offspring of their natural parents from the time the country's laws are changed" (Matter of Goorahoo: 784). Though legitimation probably could have been established through other means, it was not necessary because the laws of the country of origin made such a distinction irrelevant. The court considered the son in Goorahoo a "child" for immigration purposes and allowed him to join his father in the United States.

Both Clahar and Goorahoo show that the United States recognizes the elimination of the distinction between legitimate and illegitimate children abroad. The US government will accept this elimination instead of using its own tests to determine legitimacy. There are temporal considerations with the potential to yield unsatisfactory results on the part of the petitioner, but there is no evidence that the US government ever questions the authenticity or viability of such legislation. Yet, this government will not eliminate the distinction altogether in its own immigration system.

\subsection{Assuming legitimacy}

While the majority of the cases of an immigration court deferring to the legitimation standards of a foreign country concern immigrants from the Africa and Asia, there is also proof that Europe has begun to abolish the distinction. Matter of Pavlovic (1980) is one such case wherein a woman from Yugoslavia who had been born out of wedlock sought to immigrate. The parents in Pavlovic had never married, but the 1946 Yugoslav Constitution had eliminated all distinction between legitimate and illegitimate children (Chloros, 1970: 187). Since this was the standard at the time of Pavlovic's birth, she was able to claim that she was the "child" of her father for immigration purposes and become a lawful permanent resident. In its opinion, the court found that the Yugoslav Constitution codified that "All [Yugoslav] children... are legitimate at birth" (Matter of Pavlovic: 409). The court again ignored US standards of legitimacy and followed the customs of the immigrant's country of origin. Besides being one of the few legitimacy cases to 
concern an individual from Europe, Pavlovic can also be distinguished by the age of the law referenced by the court. The first constitution of Yugoslavia came into effect not long after the end of WWII, and its provisions considering the legitimacy of children survived until the dissolution of the country in the early nineties. This is much earlier than many of the other legitimation acts that courts have used to determine if an applicant is eligible for immigration benefits that require the status of "child". This shows that abolishing the distinction between children born in and out of wedlock is not a contemporary notion.

Not every nation has eliminated all distinctions between legitimate and illegitimate children, but these terms are becoming less and less concrete. Where children born out of wedlock were once considered impure and shameful, modern culture around the globe recognizes that they are no less human than those born to married parents are. Birth after marriage is not the only way that children avoid the moniker of illegitimate. Many countries have codified means of establishing legitimacy through either cultural or legal means. Some of these have existed for thousands of years, originating in tribal practices, while others are the product of twentiethcentury legislation. US immigration courts recognize these forms of legitimation and again use them to determine if someone qualifies as a "child" for immigration purposes. The case of Bonsu $v$. Holder (2009) is the most notable case of an immigration court using another country's legitimation standards to determine whether an individual could be considered a "child" for immigration purposes. A lower court had convicted Nana Osei Bonsu of sexual assault and unlawful restraint, which initiated removal proceedings. If Bonsu could establish that he had derived citizenship from his mother who was a naturalized citizen, the notion of removal would be moot. However, there was still the question of whether or not his father had ever legitimated him; If legitimation had occurred, Bonsu would not be able to derive citizenship from his mother ( (Bonsu v. Holder: 278). Ghana had not enacted legislation eliminating the distinction between legitimate and illegitimate children, the court was charged with determining whether the appellant had been legitimated by his father. In doing so, the court reasoned that it "must consider whether paternity has been established based on the law of the child's native country" (p. 275 ). Ghana, where Bonsu had been born, had extensive methods for proving legitimacy. The US court considered all of these methods, which involved an extensive look at Ghanaian law and customs, and ultimately it found that Bonsu had never been completely legitimated by his father in Ghana. This actually worked in his favor, and Bonsu was able to derive citizenship through his mother. The analysis of Bonsu's legitimation or lack thereof, shows the depth to which US immigration courts will probe in order to determine whether an individual is a child for immigration purposes and how much influence the system gives to the customs and practices of an immigrant's country of origin.

Analyzing foreign legitimation practices can yield positive results when legitimation has been established as well. In Matter of Kubicka (1972), another of the rare European cases, a young Polish woman sought to prove that she had been legitimated by her father after it was determined that he did not have a valid marriage to her mother. In fact, her father was still married to his first wife and the time of his marriage to Kubicka's mother, therefore nullifying the union. Polygamy is not, and has never been, legal in Poland. At the time of Kubicka's birth, the constitution of Poland did state, "The birth of a child out of wedlock does not reduce its public rights" and there were enumerated means through which a child could be legitimated by his or her father (Matter of Kubicka: 303). Since Kubicka's father had completed the process of legitimation, the court determined that she was a "child" for immigration purposes and had been when her father became a Lawful Permanent Resident. The court was not even concerned with the invalidity of Kubicka's parents' marriage because the government and laws of the country where she had been born considered her a legitimate child.

Illegitimate children face a significant number of hardships, both from societal stigma and legal discrimination. The majority of global inheritance laws focus on legitimacy and only 
contain provisions for illegitimate children to inherit once they have proven that they are the issue of the decedent. Marriage laws in some countries restrict persons born out of wedlock from ever marrying, even to other such individuals. There are even regions of the world where the birth of an illegitimate child can lead to criminal sanctions for the parents. While such practices certainly need to be addressed, the US immigration system should not cause further strife by stripping someone of their claim to legitimation while petitioning for immigration relief.

The analysis of Pavlovic, Bonsu, and Kubicka reveal that the US government will accept another country's assumption of legitimacy in immigration proceedings. It will even use negative outcomes of this assumption to direct its rulings. However, the United States will not establish its own policy of assuming legitimacy of children born from legal foreign polygamous marriages.

\subsection{Accepting polygamy}

As was stated before, this proposal is not advocating for polygamy and not suggesting that it should be seen on equal footing with monogamous marriages for immigration purposes. The US government does need to recognize that polygamy is still widely practiced and polygamous unions create children who could eventually be able to derive citizenship. It is true that polygamy is on the decline throughout the world, but that does not mean that the practice will soon be abolished everywhere. Some nations are actually enacting legislation that protects their polygamous practices. In 2014, the President of Kenya introduced a bill, commonly referred to as the Kenya Polygamy Law. The bill actually addressed marriage as a whole, and included provisions about marriage age and divorce allowances. However, the main point of the bill was to protect polygamy and it actually allowed "men to take more wives without consulting existing spouses" (Wamwara, 2019: 96). Where women were once required to take part in the selection of a potential sister-wife, they now legally have no say whatsoever.

A significant number of countries recognize polygamous marriages but only within particular groups of people. This primarily concerns Muslims living in predominantly non-Muslim countries. In some of these, the government has decided to allow Muslims to practice polygamy. Such governments will recognize a second or third spouse in the same way as the first one (Wamwara, 2019: 111). This would not present itself as an issue should the US government recognize the children of legal polygamous marriages as legitimate; the government would simply need to require petitioners to provide marriage certificates along with proof that their country of origin permits polygamous marriage. The understanding that different populations within a country have different marriage rights should not be foreign to the US as its own Mormon population is allowed to practice polygamy.

The fact of the matter is that polygamous practices still occur in the contemporary world, and the wives and children of these marriages are suffering the most. Allowing the children of such marriages to at least be able to derive citizenship from their fathers should they choose to naturalize would be both just and humane, giving them some sense of dignity in their unfortunate situations. Many of these children believe that their births were legitimate, that their parents' marriage had been in good faith, and are offended by any other notion. Rather than chastise these individuals, the US immigration system should respect the culture in which they were raised and avoid casting doubt on their very legitimacy.

Just like the practice of polygamy, the practice of deferring to another country's legitimation laws has not disappeared. On more than one occasion, the US Board of Immigration Appeals has again utilized Jamaica's legitimation standards to determine whether an individual had derived citizenship, which would end removal proceedings. In Matter of Cross (2015), the respondent was another child who had been born out of wedlock in Jamaica. His father did take 
the proper steps to have him legitimated, including having his name added to the child's birth certificate. However, by the time of Cross's birth, the Jamaican Status of Children Act “...had eliminated the legal distinction between legitimate and illegitimate children..." (Matter of Cross: 486) in Jamaica. Therefore, it did not matter that Cross's father had legitimated him. The court respected the Jamaican Status of Children Act, and held that "a person born abroad to unmarried parents can qualify as a legitimate "child" ... if he or she is born in a country or State that has eliminated all legal distinctions between children based on marital status of their parents" (p. 491). Once again, where the country of origin was ambivalent towards the legitimacy of a child, the court assumed that the individual in question was a "child" for immigration purposes.

Automatically recognizing illegitimate sons and daughters, whether they be born out of wedlock or from a polygamous union, would definitely have severe repercussions on the US immigration system and received unending criticism from conservative constituents. It would open up the floodgates with millions of people seeking to derive citizenship. This proposal merely suggests that children of marriages that have been deemed lawful by their country of birth be considered "children" for immigration purposes. It is true that should these children be allowed to immigrate, they can eventually petition for their mothers who may come to the United States and continue their polygamous union with the child's father. However, if the child's legitimation could be proved through some other means, there is nothing to stop them from doing so anyway. The rationale behind not letting children of polygamous marriages be recognized as "children" for immigration purposes is that polygamy goes against US norms and ideals. Doing so may make it seem like the United States both approves and supports polygamy. However, US laws show that the nation is not in favor of polygamy and other immigration standards do not suggest an acceptance of the practice at all. Recognizing the children of polygamous marriages would only be conferring upon them a right that they should already have; if a child is recognized as legitimate by his or her country of origin, the child should be considered a "child" for immigration purposes.

\section{Conclusion}

When there is a question of legitimation or legitimacy, immigration courts base their decision on the laws and practices of a potential immigrant's country of origin. The courts respect the customs of other countries in this regard, and give them more clout that US standards, insomuch as to completely disregard the situation of one's birth at times. Many children who would still be deemed illegitimate by US standards have been able to derive citizenship from parents who have immigrated before them. Yet many are still stuck in the mire of having to prove that they were legitimated, or in other cases not legitimated, before they can receive certain immigration benefits that should rightfully be theirs.

Legitimation standards vary across the globe, but one common theme is that it becoming less and less necessary for people to rely on the circumstances of their birth to determine their lot in life. Matter of Clahar showed that the United States accepts foreign abolishment of the distinction between legitimate and illegitimate children, but it still considers time when determining if someone is a "child" for immigration purposes. Matter of Goorahoo reinforced this notion and showed that doing so can have positive immigration outcomes for the individuals involved. Matter of Pavlovic furthered that notion and showed the abolishment of the distinction between legitimate and illegitimate children has also occurred in Europe and has occurred since the early twentieth century. Bonsu $v$. Holder showed how proving a lack of legitimation can actually be helpful for an individual in some instances. Matter of Kubicka, another of the rare European cases of legitimation, again addressed the affirmative measures that a father can take to legitimize a child born out of wedlock. Matter of Cross reemphasizes the importance that immigration courts put on the legitimation and legitimacy standards of an immigrant's country of 
origin. It also demonstrates that this practice is still used by the court today and still relevant for analysis of derivation of citizenship.

A reform in the way that US immigration courts address and recognize marriages to second and third wives, not as good faith marriages but as a means through which a legitimate child can be produces, would ease the process of derivation of citizenship and allow such children to maintain a sense of human dignity through the immigration process. Certainly, the United States is not ready to recognize all aspects of polygamous marriages abroad, although the question of whether or not immigration benefits should be extended to multiple spouses remains to be discussed. Allowing children of polygamous marriages to derive the same benefits as children of monogamous marriages is simply a way to award them equal rights and privileges in the immigration system of the United States.

\section{Acknowledgements}

This research did not receive any specific grant from funding agencies in the public commercial, or not-for-profit sectors.

The author declares no competing interests.

\section{References}

Bonsu v. Holder, 646 F. Supp. 2 d 273 (District Court, D. Connecticut 2009).

Chloros, A. (1970). Yugoslav civil law, history, family property, commentary and texts. Oxford: Clarendon Press.

Maldonado, S. (2011). Illegitimate harm: Law, stigma, anddiscrimination against nonmarital children. Florida Law Review, 345-394.

Matter of Clahar, 16 I\&N Dec. 484 (Board of Immigration Appeals 1981).

Matter of Cross, 26 I\&N Dec. 485 (Board of Immigration Appeals 2015).

Matter of Goorahoo, 20 I. \&. N. Dec. 782 (Board of Immigration Appeals 1994).

Matter of Kubicka, 14 I. \& N. Dec. 303 (Board of Immigration Appeals 1972).

Matter of Pavlovic, 17 I. \& N Dec. 407 (Board of Immigration Appeals 1980).

Silverstein, L. B., \& Auerbach, C. F. (1999). Deconstructing the Essential Father. American Psychologist, 397-407.

Wamwara, J. J. (2019). A case for legalizing polygamy in Western societies: Lessons from the global South. Law \& Inequality: A Journal of Theory and Practice, 75-96. 